\title{
Synaptic transmission of spike trains with arbitrary interspike intervals
}

\author{
Alex D Bird ${ }^{1,2,3^{*}}$, Magnus JE Richardson ${ }^{1}$ \\ From 24th Annual Computational Neuroscience Meeting: CNS*2015 \\ Prague, Czech Republic. 18-23 July 2015
}

Short-term synaptic depression, caused by depletion of releasable neurotransmitter vesicles, modulates the strength of neuronal connections in an activity-dependent manner [1,2]. Quantifying the statistics of this form of synaptic transmission requires the development of stochastic models linking probabilistic neurotransmitter release with the spike-train statistics of the presynaptic population $[3,4]$. A common approach has been to model the presynaptic spike train as either regular or a memory-less Poisson process [5] - few analytical results are available that describe the behaviour of a depressing synapse when the afferent spike train has more complex, temporally correlated statistics.

Recently, we have derived a series of results that allow for the fraction of occupied release sites and the neurotransmitter release probability to be calculated for a presynaptic spike train with arbitrary interspike interval (ISI) statistics. The results take a particularly compact form when the presynaptic spike times are generated by a renewal process, i.e. when the ISIs are independent. This encompasses a broad range of models that are currently used for circuit and network analyses, including the class of integrate-and-fire models. Our approach also allows for the postsynaptic voltage mean and variance to be calculated, which in turn allows for an approximation of the firing rate of a neuron driven by depressing synapses from non-Poissonian presynaptic neurons (Figure 1).

These results will allow for the incorporation of more complex and physiologically relevant firing patterns

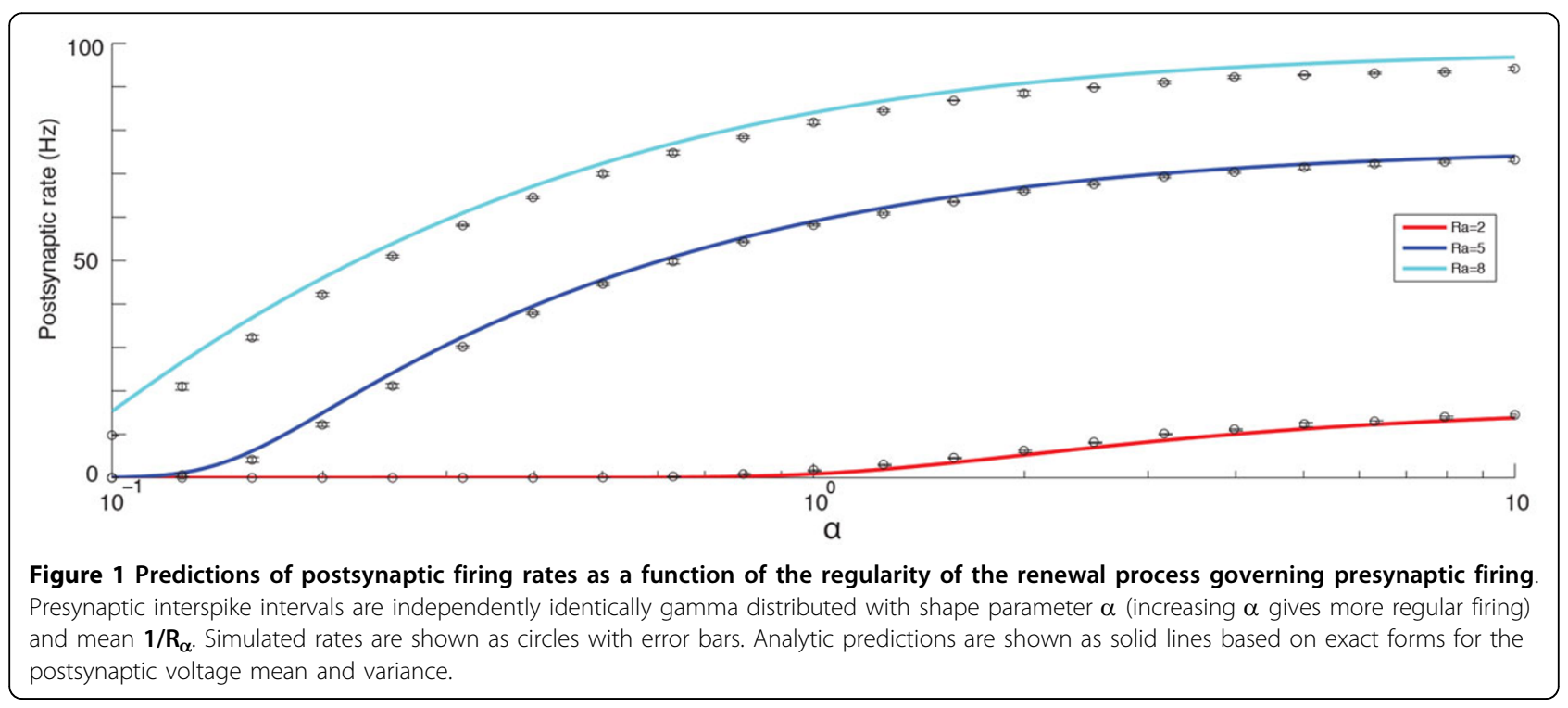

\footnotetext{
* Correspondence: a.d.bird@warwick.ac.uk

'Warwick Systems Biology Centre, University of Warwick, Coventry, UK

Full list of author information is available at the end of the article
}

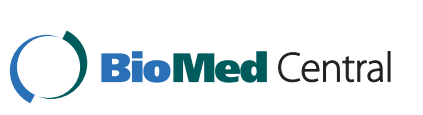

(c) 2015 Bird and Richardson This is an Open Access article distributed under the terms of the Creative Commons Attribution License (http://creativecommons.org/licenses/by/4.0), which permits unrestricted use, distribution, and reproduction in any medium, provided the original work is properly cited. The Creative Commons Public Domain Dedication waiver (http://creativecommons.org/ publicdomain/zero/1.0/) applies to the data made available in this article, unless otherwise stated. 
into future analytic studies of neuronal circuits and networks.

\section{Authors' details}

'Warwick Systems Biology Centre, University of Warwick, Coventry, UK.

${ }^{2}$ School of Life Sciences, University of Warwick, Coventry, UK. ${ }^{3}$ Warwick

Systems Biology DTC, University of Warwick, Coventry, UK.

Published: 18 December 2015

\section{References}

1. Eccles JC, Katz B, Kuffler SW: Nature of the 'endplate potential' in curarized muscle. J Neurophysiol 1941, 4(5):362-387.

2. Tsodyks M, Pawelzik K, Markram H: Neural networks with dynamic synapses. Neural Comput 1998, 10(4):821-835.

3. Fuhrmann G, Segev I, Markram H, Tsodyks M: Coding of temporal information by activity-dependent synapses. J Neurophysiol 2002, 87(1):140-148.

4. la Rocha de J, Parga N: Short-term synaptic depression causes a nonmonotonic response to correlated stimuli. J Neurosci 2005, 25(37):8416-8431.

5. Rosenbaum R, Rubin J, Doiron B: Short Term Synaptic Depression Imposes a Frequency Dependent Filter on Synaptic Information Transfer. PLoS Comput Biol 2012, 8(6):e1002557.

doi:10.1186/1471-2202-16-S1-P205

Cite this article as: Bird and Richardson: Synaptic transmission of spike trains with arbitrary interspike intervals. BMC Neuroscience 2015 16(Suppl 1):P205.

\section{Submit your next manuscript to BioMed Central} and take full advantage of:

- Convenient online submission

- Thorough peer review

- No space constraints or color figure charges

- Immediate publication on acceptance

- Inclusion in PubMed, CAS, Scopus and Google Scholar

- Research which is freely available for redistribution

Submit your manuscript at www.biomedcentral.com/submit 